\title{
(2)

\section{ANÁLISE DE VIABILIDADE ECONÔMICA REGULATÓRIA À CRIAÇÃO DE COOPERATIVA DE CONSUMO DE ENERGIA ELÉTRICA - O CASO DO SETOR ELÉTRICO BRASILEIRO NA SEGUNDA DÉCADA DO SÉCULO XXI}

\section{ECONOMIC AND REGULATORY FEASIBILITY ANALYSIS FOR CREATION OF AN ELECTRICITY CONSUMER COOPERATIVE - THE CASE OF BRAZILIAN ELECTRICITY SECTOR IN THE SECOND DECADE OF THE CENTURY XXI}

\author{
Fred Leite Siqueira Campos* E-mail: fredlsc@outlook.com \\ Fabio do Lago Ramos** E-mail: fabio.ramos@ccee.org.br \\ Beatriz Marcondes de Azevedo* - biabizzy@gmail.com \\ *Universidade Federal de Santa Catarina (UFSC), Florianópolis, SC \\ **Câmara de Comercialização de Energia Elétrica (CCEE), São Paulo, SP
}

Resumo: O setor elétrico brasileiro vem enfrentando problemas, nos últimos anos, para conciliar a demanda crescente de energia com restrições hidrológicas e econômicas. Neste cenário, o governo (como agente econômico regulatório principal) vem tomando decisões que visam, primariamente, garantir a estabilidade de suprimento de energia ao País, ações estas que ao mesmo tempo em que resolvem problemas importantes para o mercado regulado e, consequentemente, à população, geram impactos indiretos para o mercado livre de energia. De forma complementar aos modelos de comercialização existentes atualmente, este trabalho avalia a viabilidade da implantação do modelo de cooperativa de consumo à comercialização de energia elétrica no mercado livre brasileiro, como forma de mitigar riscos e reduzir restrições existentes para pequenos e médios consumidores. Para isso, além de uma revisão bibliográfica sobre os conceitos aplicáveis, são explorados dados reais sobre preço da energia elétrica, o seu consumo e sua demanda futura. Assim, concluiu-se que a criação de uma cooperativa de consumo de energia elétrica (para o cenário brasileiro atual - século XXI) é viável do ponto de vista econômico e regulatório, podendo oferecer diversos serviços à garantia do suprimento e à redução do custo de energia elétrica para seus cooperados.

Palavras-chave: Viabilidade econômica regulatória. Cooperativa de consumo. Setor elétrico brasileiro.

\begin{abstract}
The Brazilian electric sector has been facing problems in recent years to accommodate the growing demand for energy with hydrological and economic constraints. In this scenario, the government (as the main regulatory economic agent) is taking decisions aimed primarily to ensure energy supply stability to the country. However, these actions while solving important problems for the regulated market and consequently the population, also generate indirect impacts on the free energy market. Complementarily to existing marketing models, this study evaluates the feasibility of a consumer cooperative implementation model for the electricity trade in the Brazilian free market as a way to mitigate risk and reduce restrictions for small and medium consumers. Therefore, in addition to a biographical review of the applicable concepts, real data on electricity prices, consumption and future demand are explored. Thus, it was concluded that the creation of an electricity consumer cooperative (for the current Brazilian scene - XXI century) is viable from both economic and regulatory points of view and can offer various services to guarantee supply and cost reduction to its members.
\end{abstract}

Keywords: Regulatory and economic viability. Consumer Cooperative. Brazilian electric sector. 


\section{INTRODUÇÃO}

Nos últimos dois anos (2013-2014), o setor elétrico brasileiro enfrentou uma série de problemas a serem resolvidos para garantir o suprimento de energia ao País, como renovação de concessões de geração de energia vincendas (por meio da MP 579) e à escassez de chuva, ocorrida neste período, que elevou os custos da energia elétrica.

Para garantir a solução destes problemas e ao mesmo tempo buscar a modicidade tarifária para o consumidor final, um dos objetivos do modelo vigente do setor de energia elétrica, as decisões tomadas pelo governo geraram impactos indiretos para o mercado livre de energia.

Com relação à elevação de custos, ao mesmo tempo em que se buscou uma redução na tarifa da energia elétrica para os consumidores finais, o que gera um estímulo ao consumo, o país passou por um momento de escassez de chuva, o que gerou o despacho intenso de usinas termoelétricas, que tem seu custo elevado em comparação com as hidroelétricas. Este despacho resultou em grandes custos para as empresas distribuidoras, que tiveram que adquirir esta energia para honrar com seus compromissos, acumulando dívida na casa de bilhões.

Devido ao fato do Brasil ter uma matriz energética com grande dependência hidroelétrica, a hidrologia, atualmente, está no centro do modelo de operação do setor elétrico. A estimativa de chuva para os próximos cinco anos, por exemplo, é o que define por meio de modelos matemáticos se hoje devemos utilizar mais energia termoelétrica para poupar água e, consequentemente, baliza o valor dos contratos de energia.

Caruzzo e Nogueira (2015) corroboram este entendimento assinalando que a produção de energia elétrica no Brasil acontece predominantemente nas centrais hidrelétricas e o montante produzido apresenta uma direta variação sazonal em função das condições hídricas. Tal fato tem como implicação, oscilações nos custos de energia elétrica conforme os períodos secos e úmidos.

Com relação à MP 579, depois convertida na Lei $n^{\circ} 12.783$, de 11 de Janeiro de 2013 , houve uma redução de receita das geradoras que tiveram sua concessão renovada de forma antecipada em 2013, em troca de uma redução no valor dos seus contratos de suprimento.

O governo tem, por sua vez, gerado planos para contornar as situações apresentadas, seja por meio de apoio direto por fundos específicos (como a CDE) ou pela viabilização de financiamentos junto a grandes bancos.

Porém, por mais que este cenário seja conjuntural e sua solução possa exigir, inclusive, a mudança de regras ou de aspectos do modelo do setor elétrico brasileiro, a verdade é que para os agentes privados, como pequenas, médias e grandes indústrias que compram sua energia no mercado livre, o excesso de intervencionismo do estado acaba sendo interpretado como maior instabilidade econômica, em um ambiente que já possui suas próprias variáveis de instabilidade (no caso, a hidrologia). 
Mas, para facilitar o entendimento dos impactos citados acima nos agentes privados, apresento abaixo aspectos importantes de sua atuação:

- Geradores, distribuidores e comercializadores - eles têm no setor elétrico seu core business, ou seja, vivem, exclusivamente, para operar segundo as regras do setor. Como qualquer outro mercado, seus principais players precisam aprimorar constantemente sua estratégia de atuação de acordo com as alterações do setor, de forma a garantir sua sustentabilidade e lucratividade;

- Consumidores - mesmo na classe dos consumidores livres de energia é possível fazer uma subdivisão em relação ao envolvimento e entendimento do setor elétrico. Grandes consumidores, como os eletro-intensivos (por exemplo: produtores de alumínio), por terem no gasto com a energia elétrica um valor considerável e/ou uma fatia relevante dos seus insumos, acabam contando com especialistas na área de comercialização de energia elétrica para apoiar nas análises de contratação e adequação às regras do setor (sejam internos ou terceirizados com consultorias e comercializadoras de energia elétrica). Porém, os pequenos consumidores livres, que são aquelas pequenas e médias empresas que possuem em sua matriz de insumos gastos mais relevantes, não podem e nem tem o interesse em montar equipes para se aprofundarem na legislação do setor elétrico. Para estas empresas, o consumo de energia elétrica é apenas mais uma despesa a ser avaliada e paga mensalmente e o seu core business está muito longe de se relacionar como o setor elétrico (como, por exemplo, shopping centers ou redes de supermercado). Estas empresas contam, em sua grande maioria, com o apoio de comercializadoras de energia, que fazem toda a gestão dos contratos.

Como em qualquer operação baseada na compra de commodities, os benefícios de redução de custos vêm acompanhados de maiores riscos operacionais, que devem ser geridos pela empresa. No setor elétrico não é diferente e a opção de um consumidor em realizar a sua compra de energia por meio de contratos de livre negociação, em detrimento de adquirir sua energia diretamente com a distribuidora local, também traz riscos de exposição aos valores da energia elétrica e outras obrigações financeiras do mercado de energia no Brasil, como o rateio de inadimplências.

A partir do panorama apresentado, este trabalho tem o objetivo de avaliar a eficácia de um modelo de negócio alternativo, baseado na estrutura de cooperativas de consumo, para atender (com maior transparência e menor risco) estes (pequenos) consumidores livres (YILDIZ, 2015 e BAUWENS, 2014).

Realizar uma operação de compra de insumo, neste caso energia, por meio de uma cooperativa de consumo pode trazer como principais benefícios, (i) a redução de custos pela compra em grande quantidade (ganho em escala), (ii) a flexibilidade de contratação de acordo com o perfil de consumo da empresa, (iii) a redução de riscos pela viabilização de geração própria para atender os cooperados, e (iv) o oferecimento 
ainda de assessoria especializada no setor aos cooperados, contando com maior simetria de informação.

Nos capítulos a seguir serão apresentados, com mais detalhes, conceitos do setor elétrico (relevantes para o trabalho), e também os conceitos de cooperativas e as características de uma cooperativa de consumo (como ela pode ser utilizada para a atuação no setor elétrico e como recentes alterações na regulação do setor elétrico pode viabilizar este modelo de negócio). O método adotado para este trabalho foi trazer, inicialmente, uma revisão biográfica sobre o modelo de comercialização de energia e o modelo do cooperativismo no Brasil, suas características e funcionamento.

$\mathrm{Na}$ sequência serão apresentados os dados que embasam o cenário de demanda e a estimativa de crescimento do mercado de energia elétrica brasileiro, possibilitando uma análise sobre o cenário de contratação de energia para os consumidores livres e uma discussão sobre a proposta de operacionalização do modelo de cooperativa de consumo como forma de atender possíveis restrições de contratação.

\section{MODELO VIGENTE DE COMERCIALIZAÇÃO DE ENERGIA}

Segundo o site da CCEE (2014a), o modelo atual do setor elétrico brasileiro, vigente a partir de 2003, tem como objetivos:

- Promover modicidade tarifária;

- Garantir segurança de suprimento de energia elétrica;

- Promover a inserção social no Setor Elétrico Brasileiro, em particular pelos programas de universalização de atendimento.

Com a implantação do modelo, foram criados dois ambientes de compra e venda de energia elétrica, o Ambiente de Contratação Regulada (ACR) do qual participam agentes de geração e de distribuição de energia; e o Ambiente de Contratação Livre (ACL), do qual participam agentes de geração, comercializadores, importadores e exportadores de energia e consumidores livres.

Atuando de forma complementar aos dois ambientes citados acima, há ainda o mercado de curto prazo (MCP), também conhecido como mercado de diferenças, no qual se promove o ajuste entre os volumes contratados e os volumes medidos de energia.

No ambiente de contratação regulada (ACR), o objetivo é viabilizar a contratação de energia para abastecimento das distribuidoras de energia elétrica, que por sua vez tem a responsabilidade de atender a população em geral e as empresas que não adquirem sua energia no mercado livre (entenderemos a seguir), e que se encontram em sua área de atuação.

No Ambiente de Contratação Livre (ACL), foco deste trabalho, o objetivo é viabilizar um mercado em que os agentes de geração, comercializadores, importadores e exportadores de energia e consumidores livres que atendam as condições previstas na regulação, possam realizar compra e venda de energia de forma bilateral e com livre escolha de fornecedores. 
A figura abaixo, de CCEE (2014b), ilustra as relações contratuais nos ambientes ACL e ACR.

Figura 1 - Relações contratuais nos ambientes de contratação livre e regulada

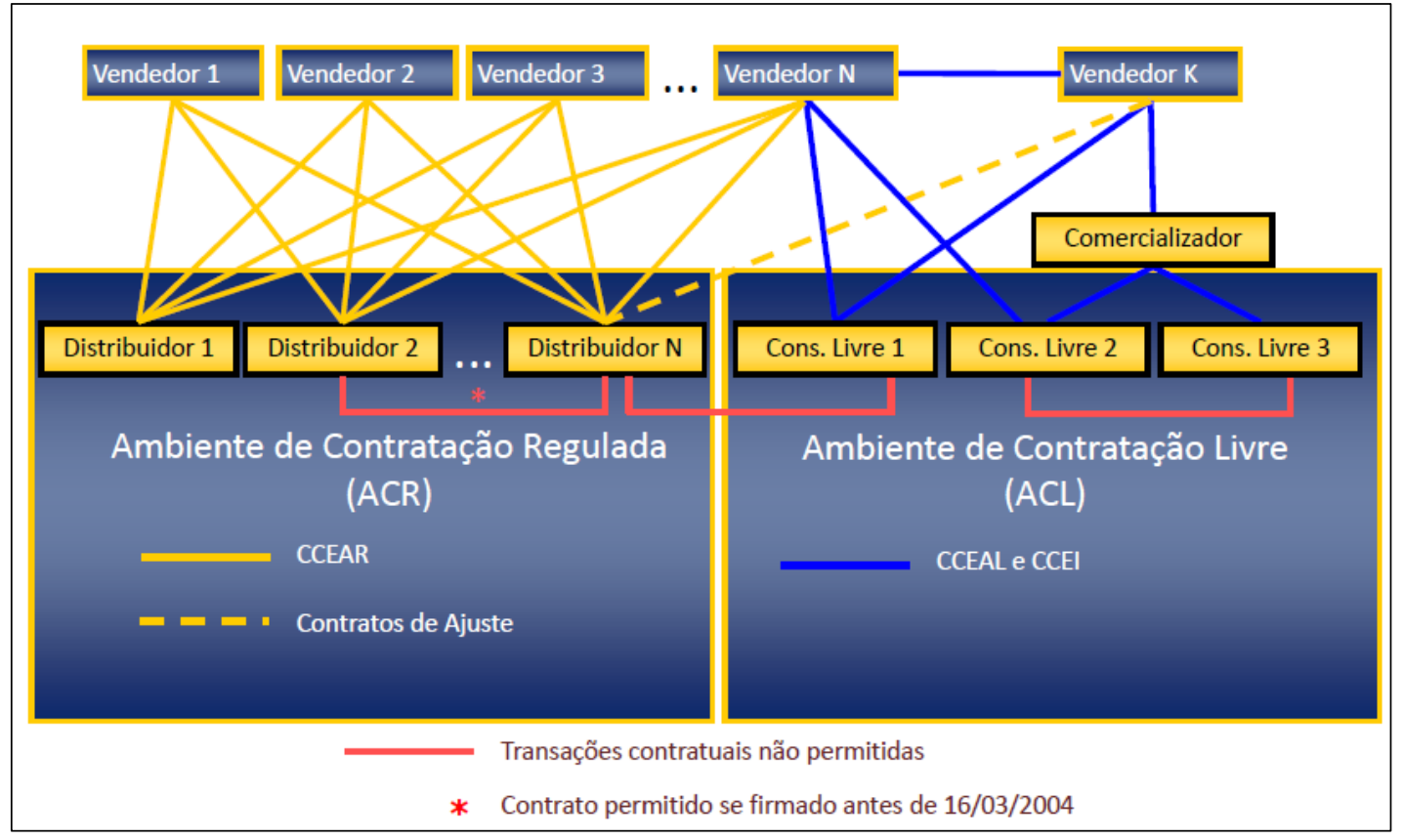

Fonte: CCEE (2014b)

Neste contexto é importante detalhar a atuação do comercializador de energia, que ocupa um papel central no encontro de demanda e oferta.

Segundo ABRACEEL (2014), geradores e consumidores de energia têm muitas vezes objetivos distintos. Geradores desejam maximizar preço de venda, o volume vendido e vender conforme sua produção. Procuram contratos de longo prazo para lastrear financiamentos. Já os compradores buscam minimizar preço de compra, segurança no atendimento, comprar conforme suas curvas de carga e prazos menores de contratação.

Todos querem reduzir a possibilidade de estarem expostos a riscos e penalidades. Cabe aos comercializadores atuar reduzindo os chamados custos de transação, fazendo o encontro eficiente entre geradores e consumidores.

Ainda, segundo ABRACEEL (2014), os comercializadores desenvolvem produtos e associam serviços ao produto energia, em um mercado cada vez mais competitivo, inovador e com foco nas necessidades de seus clientes. De forma análoga a outros mercados de commodities, o mercado de comercialização de energia passa por um processo de modernização e sofisticação, importando e adaptando ferramentas já usadas em outros mercados, tais como opções, futuros, swaps, contratos a termo e outros.

Também, ocupando um papel central no mercado livre, é importante diferenciar os tipos existentes de consumidores livres de energia elétrica. Abaixo apresentamos a definição de CCEE (2014a) para consumidor livre e consumidor livre especial. 
- Consumidor Livre: consumidor que, atendendo aos requisitos da legislação vigente e tendo a demanda mínima de 3MW (sob qualquer tensão), pode escolher seu fornecedor de energia elétrica (gerador e/ou comercializador) por meio de livre negociação.

- Consumidor Especial: consumidor com demanda entre $500 \mathrm{~kW}$ e 3MW, que tem o direito de adquirir energia de qualquer fornecedor, desde que a energia adquirida seja oriunda de fontes incentivadas especiais (eólica, Pequenas Centrais Hidrelétricas - PCHs, biomassa ou solar).

Uma vez entendidas as características e a diferença dos mercados ACR e ACL, é necessário se entender como o mercado de curto prazo (MCP) atua de forma complementar para garantir a liquidação financeira integral do mercado de energia no Brasil.

O mercado de curto prazo (MCP) é contabilizado em um processamento mensal em que são contemplados, entre outros, o montante de energia contratado, que deve ser registrado no sistema da CCEE conforme citado acima, e o montante de energia verificado, dado que é medido pela CCEE junto às unidades de medição para faturamento dos agentes, gerando ao seu final as exposições dos agentes a serem pagas no mercado de curto prazo (CCEE, 2013b).

A figura 2 mostra o funcionamento do MCP.

Figura 2 - Funcionamento do mercado de curto prazo (MCP)

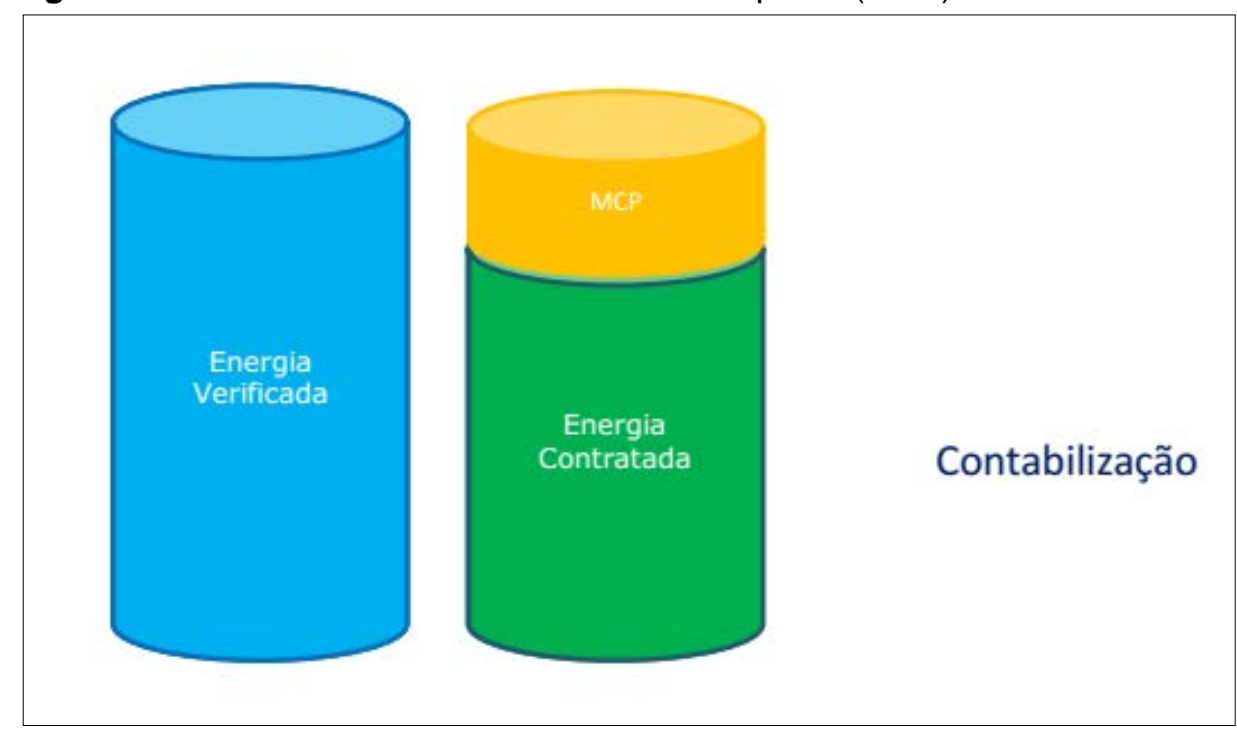

Fonte: CCEE (2014b)

Para a realização da liquidação financeira do MCP, a CCEE também é responsável pelo cálculo do Preço de Liquidação das Diferenças - PLD. Este preço é calculado levando em consideração o custo futuro da energia no Brasil, o que gera a volatilidade de preços citada na introdução deste trabalho em momentos de escassez de água. 
Segundo a CCEE (2014c), em função da preponderância de usinas hidrelétricas no parque de geração brasileiro, são utilizados modelos matemáticos para o cálculo do PLD, que têm por objetivo encontrar a solução ótima de equilíbrio entre o benefício presente do uso da água e o benefício futuro de seu armazenamento, medido em termos da economia esperada dos combustíveis das usinas termelétricas.

Com base nas condições hidrológicas, na demanda de energia, nos preços de combustível, no custo de déficit, na entrada de novos projetos e na disponibilidade de equipamentos de geração e transmissão, o modelo de precificação obtém o despacho (geração) ótimo para o período em estudo, definindo a geração hidráulica e a geração térmica para cada sub mercado. Como resultado desse processo, são obtidos os Custos Marginais de Operação (CMO) para o período estudado, para cada patamar de carga e para cada sub mercado.

De acordo com Varian (2012, p. 397), conceitua-se o custo marginal como à taxa de variação do custo pela variação da produção, ou o acréscimo do custo total pela produção de mais uma unidade. Para exemplificar, pode-se avaliar duas produções distintas. Na primeira produção, em que o custo variável unitário é o mesmo, se aumentar a produção o custo marginal deverá reduzir, pois, são mais unidades de produção dividindo o mesmo custo fixo e reduzindo o custo unitário total.

O entendimento do funcionamento complementar do ambiente ACR, ACL, do mercado de curto prazo e sua liquidação pelo PLD será importante para os debates sobre o modelo cooperativista como opção de comercialização. Porém descreveremos como adendo ao modelo vigente duas regulações recentes e seus conceitos como contribuintes para a viabilidade do modelo de atuação em análise.

A primeira regulação abordada é a Resolução Normativa da ANEEL n 570 (ANEEL, 2013), que cria a figura do comercializador varejista no mercado livre de Energia Elétrica.

Segundo COMERC (2013), o papel do comercializador varejista permitirá a gestão integral da energia e demais responsabilidades de consumidores livres por um agente comercializador integrante da CCEE. Os geradores com capacidade instalada inferior a $50 \mathrm{MW}$, não comprometidos no ACR, também poderão ser representados por agentes comercializadores ou geradores que tenham obtido aprovação do Conselho de Administração da CCEE.

Ainda, conforme COMERC (2013), a criação desta figura facilitará a migração de pequenos consumidores com demanda entre 0,5MW e 3MW. Os consumidores especiais representam atualmente $45 \%$ do número de agentes na CCEE e, a partir da comercialização varejista, abrangerá um número maior de centros comerciais, hospitais, cadeia de lojas, pequenas e médias indústrias que delegarão a gestão de energia aos agentes comercializadores de grande porte e com experiência de gestão.

Para o contexto deste trabalho, esta regulação permitiria uma atuação junto à cooperativa de consumo de forma simplificada para seus cooperados, que não precisariam aderir a CCEE de forma individualizada, arcando com as responsabilidades de participar diretamente de sua operação. 
A segunda regulação que será abordada é a Resolução Normativa da ANEEL no 611 (ANEEL, 2014a), que autoriza a cessão de montantes de energia elétrica e de potência por consumidores livres e especiais. Com isso passa a ser possível que consumidores livres e especiais também negociarem seus contratos de energia e potência entre si.

Antes desta resolução esta atividade era restrita a outras classes, sendo proibido que consumidores pudessem, por exemplo, negociar as sobras de seus contratos de energia com outros consumidores. Esta é uma petição antiga da classe, e sua implantação trouxe em teoria maior liquidez para o mercado livre, além de dar maior flexibilidade de atuação para os consumidores.

Para o contexto deste trabalho, esta regulação permitiria que a cooperativa atuasse viabilizando a negociação de sobras contratuais mensais entre os seus cooperados consumidores, reduzindo assim possíveis exposições que os mesmos teriam no mercado de curto prazo.

\section{O COOPERATIVISMO}

O cooperativismo, no Brasil, foi regulamentado em 1971, como uma forma de possibilitar que empresas se juntassem para serem mais competitivas em seus mercados. As informações deste capítulo foram compiladas a partir da regulação e do Manual de cooperativas do SEBRAE (2009).

Em primeiro lugar, é importante citar os principais benefícios ou vantagens estratégicas que a atuação em cooperação traz para as empresas ou indivíduos. Dentre os benefícios, pode-se citar: fortalecer o poder de compras, compartilhar recursos, combinar competências, dividir o ônus de realizar pesquisas tecnológicas, partilhar riscos e custos para explorar novas oportunidades e oferecer produtos com qualidade superior e diversificada. Essas vantagens estão associadas ao fato de essas ações, muitas vezes, não poderiam ser realizadas pelas empresas de forma isolada sem um alto custo envolvido.

As cooperativas, no Brasil, estão regulamentadas na Constituição Federal (BRASIL, Constituição, 1998), no Novo Código Civil (BRASIL, Código Civil, 2002), e também na LEI no 5.764/71 (BRASIL, Lei $n^{\circ} 4.740$, de 15 de julho de 1965, 1965), conhecida como Lei do Cooperativismo. Nesta regulamentação estão descritas as regras de constituição e organização para o modelo cooperativista no Brasil. Em alguns Estados da Federação, encontra-se legislação complementar para atender especificidades estaduais, mas que são subordinadas às leis federais.

SEBRAE (2009) complementa, ainda, que o modelo cooperativo tem sido usado para viabilizar negócios em vários campos de atuação. Para efeito de organização do Sistema Cooperativo, eles estão organizados por ramos conforme a área em que atuam. São eles:

- Cooperativas Agropecuárias - reúnem produtores rurais ou agropastoris e de pesca, que trabalham de forma solidária na realização das várias etapas da cadeia produtiva; 
- Cooperativas de Consumo - caracterizam-se pela compra em comum de artigos de consumo para seus cooperantes, buscando diminuir o custo desses produtos;

- Cooperativas de Crédito - são sociedades de pessoas destinadas a proporcionar assistência financeira a seus cooperantes;

- Cooperativas Educacionais - surgiram como uma solução para a crise que enfrentavam as escolas brasileiras. Pais e alunos se uniram para enfrentar a falta de estrutura do ensino público e o alto custo das mensalidades das escolas particulares.

- Cooperativas Especiais - são cooperativas constituídas por pessoas que precisam ser tuteladas, como deficientes físicos e mentais, dependentes de acompanhamento psiquiátrico permanente, dependentes químicos, pessoas egressas de prisões, entre outros;

- Cooperativas de Habitação - são cooperativas destinadas à construção, manutenção e administração de conjuntos habitacionais para seu quadro social. As cooperativas desse tipo utilizam o autofinanciamento ou as linhas de crédito oficiais para produzir imóveis residenciais com preços abaixo do que se pratica normalmente no mercado, conseguidos com a gestão eficiente dos recursos;

- Cooperativas de Infraestrutura - antes denominadas de "Energia/Telecomunicações e Serviços", são cooperativas cuja finalidade é atender direta e prioritariamente o próprio quadro social com serviços de infraestrutura;

- Cooperativas de Mineração - têm a finalidade de pesquisar, extrair, lavrar, industrializar, comercializar, importar e exportar produtos minerais;

- Cooperativas de Produção - formam um dos ramos mais expressivos de cooperativismo, composto pelas cooperativas dedicadas à produção de um ou mais tipos de bens e mercadorias, sendo os meios de produção coletivos, através da pessoa jurídica, e não individual, do cooperante;

- Cooperativas de Saúde - são as cooperativas que se dedicam à recuperação e á preservação da saúde humana. É um dos ramos que mais rapidamente cresceu nos últimos anos, incluindo médicos, enfermeiros, dentistas, psicólogos e profissionais afins.

- Cooperativas de Trabalho - são sociedades de pessoas que, reciprocamente, se obrigam a contribuir com bens ou serviços para o exercício de uma atividade econômica, de proveito comum, sem objetivo de lucro, uma vez que o resultado do trabalho é dividido ente os cooperantes.

Ainda, é importante discorrer sobre as cooperativas em operação no setor elétrico e que podem trazer dúvida quanto à discussão deste trabalho. No setor elétrico já existem diversas cooperativas em operação, mas elas existem, principalmente, no modelo citado acima de 'Cooperativas de Infraestrutura', que inclusive como abordado eram antes denominadas de "Cooperativas de Energia/Telecomunicações e Serviços". 
Enquanto que esta modalidade já é empregada há algum tempo no setor, tendo sua raiz na necessidade de união para viabilização de eletrificação rural, este trabalho aborda a utilização da modalidade 'Cooperativas de Consumo' para discutir um modelo de compra em comum de energia elétrica no mercado livre para atender seus cooperados, focando não na viabilização de infraestrutura em comum, mas sim no ganho de escala e na redução de custo que esta modalidade pode trazer (YILDIZ, 2015 e BAUWENS, 2014).

\section{MATERIAIS E MÉTODOS}

Quando se avaliam os conceitos de metodologia de pesquisa cientifica, identifica-se que existem diversos tipos de pesquisa que podem ser aplicados a um trabalho acadêmico. Segundo Kauark (2010), pode-se classificar uma pesquisa por sua natureza, pela forma como aborda o problema, pelos seus objetivos, do ponto de vista dos procedimentos aplicados na mesma, entre outros.

Com base na tipologia apresentada pela autora em sua obra, pode-se dizer que este trabalho é uma pesquisa aplicada, qualitativa, descritiva e bibliográfica sobre: (i) o modelo vigente de comercialização de energia elétrica, no Brasil, descrevendo sua divisão de mercados, o funcionamento dos mesmos e seus participantes; e, (ii) e sobre o modelo vigente do cooperativismo no Brasil, descrevendo seus princípios de funcionamento, os possíveis ramos de atuação e suas características.

$\mathrm{Na}$ sequência da presente pesquisa, são apresentados dados que embasam o cenário de demanda e estimativa de crescimento do mercado de energia elétrica no momento, possibilitando uma discussão sobre o cenário de contratação de energia para os consumidores livres e suas restrições e, por fim, a proposta de operacionalização do modelo de cooperativa de consumo de energia elétrica para o mercado livre, como forma de atender as restrições anteriormente citadas.

\section{RESULTADOS E DISCUSSÃO}

Como forma de oferecer uma alternativa de modelo de comercialização de energia elétrica para consumidores livres de energia no Brasil, este trabalho encontrou no modelo de cooperativa de consumo uma opção válida e que agrega ganho financeiro com redução de riscos.

As principais características do modelo em questão reúnem ganhos já conhecidos para cooperativas, como ganho em escala e poder de negociação, mas também benefícios específicos da aplicação deste modelo às restrições que serão abordadas a seguir para problemas que veem sendo enfrentados pelo setor elétrico. É importante citar ainda que as recentes alterações da regulação, abordadas no capítulo 2, são importantes para a viabilidade do modelo.

Na sequência do trabalho, apresentam-se: (i) uma breve contextualização sobre a demanda atual de energia elétrica e sua estimativa de crescimento, para os 
próximos anos; (ii) uma análise do cenário de contratação de energia para os consumidores livres, público-alvo do modelo de negócio apresentado, e seus desafios imediatos; e, (iii) uma abordagem da operacionalização do modelo de cooperativa proposto e seus benefícios.

\subsection{Demanda atual de energia elétrica e sua estimativa de crescimento para os próximos anos}

Conforme contextualizado anteriormente, o mercado de energia elétrica no Brasil é dividido em dois ambientes de contratação de energia, o Ambiente Regulado (ACR) e Ambiente Livre (ACL). Segundo CCEE (2015), os dois ambientes juntos somaram, em novembro de 2014, um consumo de 62.393 MW (médio), porém, o que é importante avaliar para este trabalho é a representatividade de cada ambiente neste total.

A figura 3 apresenta um histórico de consumo de cada mercado (ACR e ACL) para os últimos três anos, em que é possível verificar uma representatividade média de $26 \%$ do mercado livre (\% ACL), no total do consumo; em comparação com $74 \%$ do mercado regulado (\% ACR).

Avaliando-se os valores apresentados pela figura 3, é possível se constatar, ainda, que houve maior variação no consumo do mercado regulado (ACR), de aproximadamente $12,5 \%$ do consumo para este período, em comparação com $2,5 \%$ do consumo para o mercado livre (ACL).

Figura 3 - Gráfico com energia consumida no mercado livre e no mercado regulado - entre novembro 2011 e novembro 2014

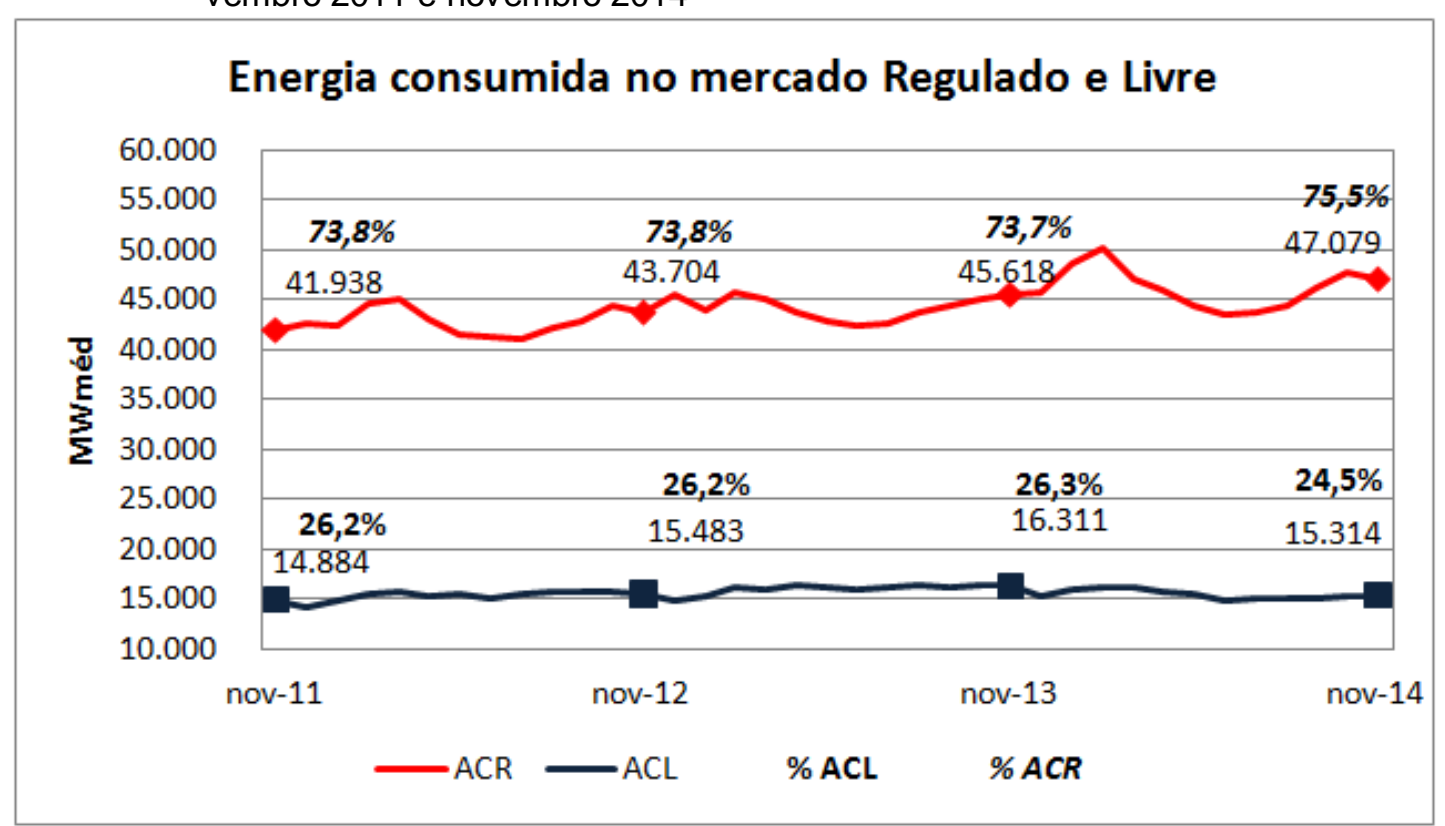

Fonte: CCEE (2013c, 2014d e 2015a)

Outro dado importante para o entendimento da demanda e crescimento do mercado livre de energia é a quantidade e variação de consumidores atuantes no mesmo ao longo do tempo. 
A figura 4 apresenta um histórico da quantidade de consumidores atuantes no mercado livre de energia $(A C L)$ para os mesmo três anos (Nov. de 2011 à Nov. de 2014), onde é possível verificar um crescimento de $65,5 \%$ para o período $(2,5 \%$ entre 2013 e 2014), com predominância de crescimento para o tipo de consumidores especiais (conceito também já abordado neste trabalho).

Figura 4 - Gráfico com a quantidade de consumidores no mercado livre de energia entre novembro 2011 e novembro 2014

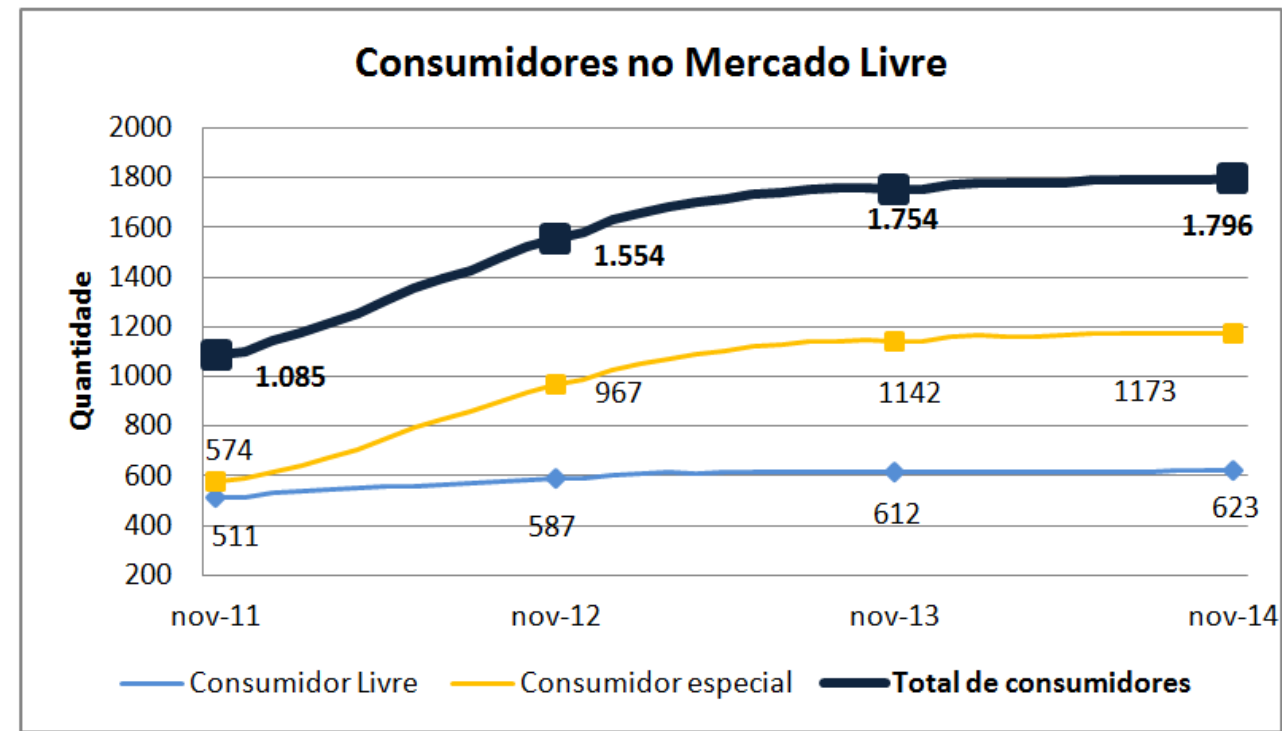

Fonte: CCEE (2013c, 2014d e 2015a)

Enquanto que os dados acima apresentam um histórico em que é possível se entender o crescimento e o comportamento do mercado livre de energia nos últimos anos, são apresentados abaixo dados relacionados à previsão futura de crescimento do mercado de energia no Brasil.

A figura 5 traz dados do Ministério de Minas e Energia (MME) e da Empresa de Pesquisa Energética (EPE), relacionados à projeção de consumo anual de eletricidade no Brasil, até 2023. Os dados estão divididos por classe de consumo, mas, não fazem separação entre o mercado regulado (ACR) e o livre (ACL). Porém, são dados relevantes para o entendimento de que há um crescimento de consumo previsto de 4,0\% (médio) ao ano. 
Figura 5 - Previsão de consumo anual de eletricidade, entre 2013 e 2023

\begin{tabular}{|c|c|c|c|c|c|}
\hline \multirow{2}{*}{ Ano } & Residencial & Industrial & Comercial & Outros & Total \\
\hline & \multicolumn{5}{|c|}{ GWh } \\
\hline 2014 & 129.983 & 191.333 & 87.378 & 72.691 & 481.385 \\
\hline 2018 & 154.879 & 222.148 & 108.359 & 83.271 & 568.657 \\
\hline 2023 & 189.934 & 257.714 & 142.660 & 98.682 & 688.990 \\
\hline Periodo & \multicolumn{5}{|c|}{ Variação (\% a.a.) } \\
\hline 2013-2018 & 4,4 & 3,8 & 5,3 & 3,4 & 4,2 \\
\hline $2018-2023$ & 4,2 & 3,0 & 5,7 & 3,5 & 3,9 \\
\hline 2013-2023 & 4,3 & 3,4 & 5,5 & 3,4 & 4,0 \\
\hline Consider & açöes de Maca & irtir de julho de & Boavista a part & e 2016 ao s & lorte. \\
\hline
\end{tabular}

Fonte: MME/EPE (2014)

Em resumo, é possível constatar, pelos dados apresentados acima, que o consumo de energia elétrica prevista para o mercado brasileiro é crescente em 4,0\% (médio) ao ano, enquanto que o mercado livre tem uma representatividade de $25 \%$ no total do consumo entre ACR e ACL, com predominância (cerca de 65\%) de consumidores especiais, público alvo de uma cooperativa de consumo de energia elétrica, por serem pequenos e médios consumidores.

\subsection{Cenário de contratação de energia para os consumidores livres e seus desa- fios imediatos}

O cenário de contratação de energia no mercado livre passa, em 2014 e 2015, por um período de mudanças motivado, dentre outros fatores, pela MP 579, depois convertida na Lei $n^{\circ} 12.783$ de 11 de Janeiro de 2013.

A MP 579 trouxe um conjunto de regras para o setor elétrico, propondo a renovação das concessões dos serviços de geração, transmissão e distribuição de energia, objetivando-se uma redução do custo da energia elétrica para o Brasil.

Em resumo, ela propõe a antecipação da renovação das concessões de diversas empresas que teriam seu período vincendo, entre 2014 e 2015, com uma indenização da parcela de investimentos ainda não amortizados ou depreciados, e com condições contratuais diferentes das iniciais. As empresas não optantes pela renovação manteriam suas condições contratuais, até o prazo final da concessão, quando o governo licitará, por mais 30 anos, os empreendimentos.

A contrapartida contratual, trazida pela MP 579, é que as empresas detentoras das concessões renovadas passarão a gerar e transmitir energia com um valor regulado pelo governo, que considera apenas o custo de O\&M, partindo-se da premissa que o investimento inicial para construção dos empreendimentos já foram pagos nos contratos e se encerram com esta renovação. Na prática, segundo MEDEIROS, 2012, os contratos sofrem uma redução média de $70 \%$.

Outra contrapartida contratual, que gerou discussão e impacta a contratação no mercado livre de energia, é a condição de que a energia renovada é alocada na 
forma de cotas para as distribuidoras do mercado regulado (ACR). Esta condição foi estipulada devido ao valor mais barato do MWh destes contratos, porém, traz importantes reflexos à contratação no mercado livre de energia, a redução da energia disponível para negociação.

Segundo cálculos apontados nos relatórios, ao mercado, de TRADE ENERGY (2012 e 2014a), cerca de 2.500 MW (média) serão retirados do mercado livre com a implantação das cotas. Este montante representa cerca de $15 \%$ da demanda atendida neste mercado que, por sua vez, representa cerca de $60 \%$ da demanda industrial do país.

Por ser justamente a energia mais barata disponível para contratação, por serem de empreendimentos hidroelétricos, e por levar a uma oferta mais restrita no mercado livre, outros impactos indiretos apontados pelos relatórios são: o encarecimento da energia contratada e a dificuldade de contratação da mesma.

\subsection{Operacionalização do modelo de cooperativa de consumo de energia elé- trica para o mercado livre}

Os impactos citados acima são discutidos no setor de energia, principalmente pelas associações de consumidores livre que apontam como necessárias soluções para aumentar a disponibilidade de energia destinada ao mercado livre.

Nesta linha, abordou-se a aplicabilidade do modelo de negócio de uma cooperativa de consumo para atender as restrições do mercado. Esta análise será dividida em tópicos relacionados aos riscos atuais identificados para os consumidores de energia.

\subsubsection{Encarecimento da energia elétrica}

Conforme apresentado no anteriormente, um dos impactos indiretos da cotização da energia elétrica, devido à MP579, será o encarecimento da energia elétrica no mercado livre.

Este é o primeiro e principal ponto atendido pelo modelo de negócio de cooperativa de consumo. Como já visto, uma cooperativa de consumo caracteriza-se pela compra em comum de artigos de consumo para seus cooperantes, buscando-se diminuir o custo desses produtos.

Ao realizarem esta união para realizar a compra da energia elétrica, pequenos e médios consumidores livres, classe em crescimento conforme dados apresentados, terão maior poder de negociação e poderão realizar ações de compra parecidas com os já praticados pelas comercializadoras, que por ter uma grande demanda para seus clientes, compram grande parte ou até mesmo toda a produção de energia de um gerador, e a revendem em contratos menores para consumidores livres.

A cooperativa, neste caso, atuaria garantindo, mesmo a pequenos consumidores, a mesma vantagem competitiva que grandes consumidores conseguem junto à suas comercializadoras, em relação a custos. 
Se focada em consumidores especiais, que conforme citado no capítulo 2 têm direito a descontos no valor da energia (se comprada de fontes alternativas), a cooperativa pode, ainda, atuar na busca de parcerias com empreendimentos de fontes renováveis, como geradores à biomassa, para garantir que este desconto seja maximizado.

\subsubsection{Dificuldade de contratação}

Outro impacto indireto (também já citado anteriormente) é a dificuldade de contratação prevista devido à alocação de energia do mercado livre para o mercado regulado.

Este segundo ponto acaba sendo atendido em parte pela atuação citada anteriormente, em que a compra, em conjunto, pode viabilizar a aquisição de grande parte ou até mesmo toda a produção de energia de um gerador, com a revenda em contratos menores para consumidores livres. A contratação desta energia para o longo prazo, desde que para o montante necessário, garante o suprimento dos contratos da cooperativa.

Porém, em um cenário de aumento de demanda, conforme dados apresentados e sendo, ainda, que haverá, em 2015, renovações de concessões a serem concluídas, pode-se ter agravamento do cenário atual de restrição de contratação. Neste contexto, pode haver, também, dificuldade de encontrar geração disponível para compra em grande quantidade, uma vez que grandes comercializadoras têm a mesma atuação e concentram grande parte de geração disponível para o mercado livre em seus portfólios.

Nesta situação, a cooperativa de consumo pode ter outra direção de atuação, não buscando a aquisição eficiente de energia no mercado, mas viabilizando novas fontes de geração.

Esta atuação pode ser vantajosa até mesmo para a redução do preço da energia adquirida, pois, é importante lembrar que de acordo com os conceitos econômicos apresentados em Varian (2012, p. 288), a energia elétrica pode ser considerada um produto de demanda inelástica, ou seja, um produto em que o aumento do preço não traz grande variação no consumo, devido ao fato deste tipo de produto ter poucos substitutos (ou quase nenhum no caso da energia elétrica). Então, neste caso, um aumento da demanda de energia (agravada com a restrição de oferta) não levará a uma redução no consumo ou substituição de produto, mas sim a um aumento no preço dos contratos.

E para evitar que os cooperados paguem altos preços em um cenário de agravamento de restrição de oferta, a viabilização de geração pela cooperativa pode ser uma alterativa tanto para garantir suprimento quanto para garantir preço acessível. Há, ainda, algumas alternativas possíveis para que a cooperativa atue neste sentido.

Uma primeira alternativa que pode ser utilizada pela cooperativa para viabilizar a geração é a realização de leilões, já praticados de forma centralizada pelo governo para a viabilização de oferta de energia necessária ao Brasil para o curto, médio e 
longo prazo. No caso da cooperativa, a realização de um leilão de energia nova buscaria atrair empresas interessadas em construir um empreendimento para atender a demanda a ser contratada para o longo prazo indicada pela cooperativa, ao mesmo tempo em que visaria se aproximar do melhor preço de compra da energia.

Observando-se os conceitos de leilão apresentados por Varian (2012, p. 338), é importante apenas se atentar ao melhor formato de leilão a ser estruturado para evitar resultados indesejados. Neste sentido, uma importante variável a ser avaliada e definida pela cooperativa será o preço inicial e máximo a ser pago pela energia, variável que pode buscar referência nos leilões em realização pela CCEE para o governo, em especial os de fontes alternativas, por viabilizarem empreendimentos de menor porte como usinas de biomassa ou PCHs.

Uma segunda alternativa, que visa reduzir a necessidade de contratação de energia por parte dos cooperados, é a cooperativa atuar na viabilização de projetos de geração própria para suas empresas atuando neste caso, também como cooperativa de consumo de equipamentos de geração, barateando também a implantação dos empreendimentos.

Para a ANEEL (2014b), a geração própria ou distribuída constitui uma tendência em diversos países, inclusive com a concessão de incentivos pelo governo. Este tipo de geração de pequeno porte tem como principais benefícios: reduzir a necessidade de investimentos em expansão da distribuição e transmissão, por poder ser alocada próxima a sua carga (ou consumo); seu baixo impacto ambiental, devido ao pequeno porte dos projetos; e a redução no carregamento das redes de transmissão e distribuição, entre outros.

Ainda segundo ANEEL (2014b), no Brasil as condições gerais para o uso de micro e mini geração distribuída aos sistemas de distribuição de energia elétrica foram definidas na Resolução Normativa $n^{\circ}$ 482, de 17 de abril de 2012, caracterizando-as com a seguinte definição: [...] A micro e a mini geração distribuída consistem na produção de energia elétrica a partir de pequenas centrais geradoras que utilizam fontes com base em energia hidráulica, solar, eólica, biomassa ou cogeração qualificada, conectadas à rede de distribuição por meio de instalações de unidades consumidoras.

Para Cristaldo e Ortega (2009), os sistemas de cogeração apesar de serem normalmente projetados para responder às necessidades das indústrias de médio e grande porte, apresentam uma significativa eficiência, uma vez que focam um mercado inovador, competitivo "voltado para os consumidores, onde os negócios apenas têm êxito se focados no interesse destes clientes finais" (p. 232).

Quanto à sua especificação, estas unidades de geração devem ter potência instalada de 0 a 100 quilowatts (micro geração) até 1 megawatt (mini geração), o que se encaixa nos perfis de consumo de consumidores livres especiais, que conforme já citado são os consumidores com demanda entre $500 \mathrm{~kW}$ e $3 \mathrm{MW}$, e até mesmo de forma complementar para os consumidores livres normais, com demanda mínima de $3 \mathrm{MW}$. 
Um fator importante para a viabilidade dos empreendimentos de geração distribuída como fonte de geração complementar ao cenário de contratação foi à inovação trazida pela resolução normativa citada, n 482, de 17 de abril de 2012, chamado de Sistema de Compensação de Energia Elétrica.

Segundo ANEEL (2014b, p.16), esse sistema permite que a energia excedente gerada pela unidade consumidora com micro ou mini geração seja injetada na rede da distribuidora, a qual funcionará como uma bateria, armazenando esse excedente até o momento em que a unidade consumidora necessite de energia proveniente da distribuidora. Dessa forma, a energia elétrica gerada por essas unidades consumidoras é cedida à distribuidora local, sendo posteriormente compensada com o consumo de energia elétrica dessa mesma unidade consumidora (ou de outra unidade consumidora de mesma titularidade).

Em resumo, nos momentos em que a central não gera energia suficiente para abastecer a unidade consumidora, a rede da distribuidora local suprirá a diferença. Nesse caso, será utilizado o crédito de energia ou, caso não haja, o consumidor pagará a diferença.

É importante pontuar que a contratação parcial junto à distribuidora local e parcial junto ao mercado livre é possível pela regulação atual, que considera este perfil como consumidor parcialmente livre.

\subsubsection{Risco de exposição ao mercado de curto prazo}

No gráfico correspondente à Figura 6 é possível visualizar, por meio dos valores de PLD calculados pela CCEE, a exposição média anual à qual os consumidores descobertos contratualmente ficaram expostos, ao longo do ano de 2014, apresentando ainda valores ocorridos para o mês de janeiro de 2015.

Figura 6 - Comportamento do PLD, entre janeiro de 2014 e janeiro de 2015

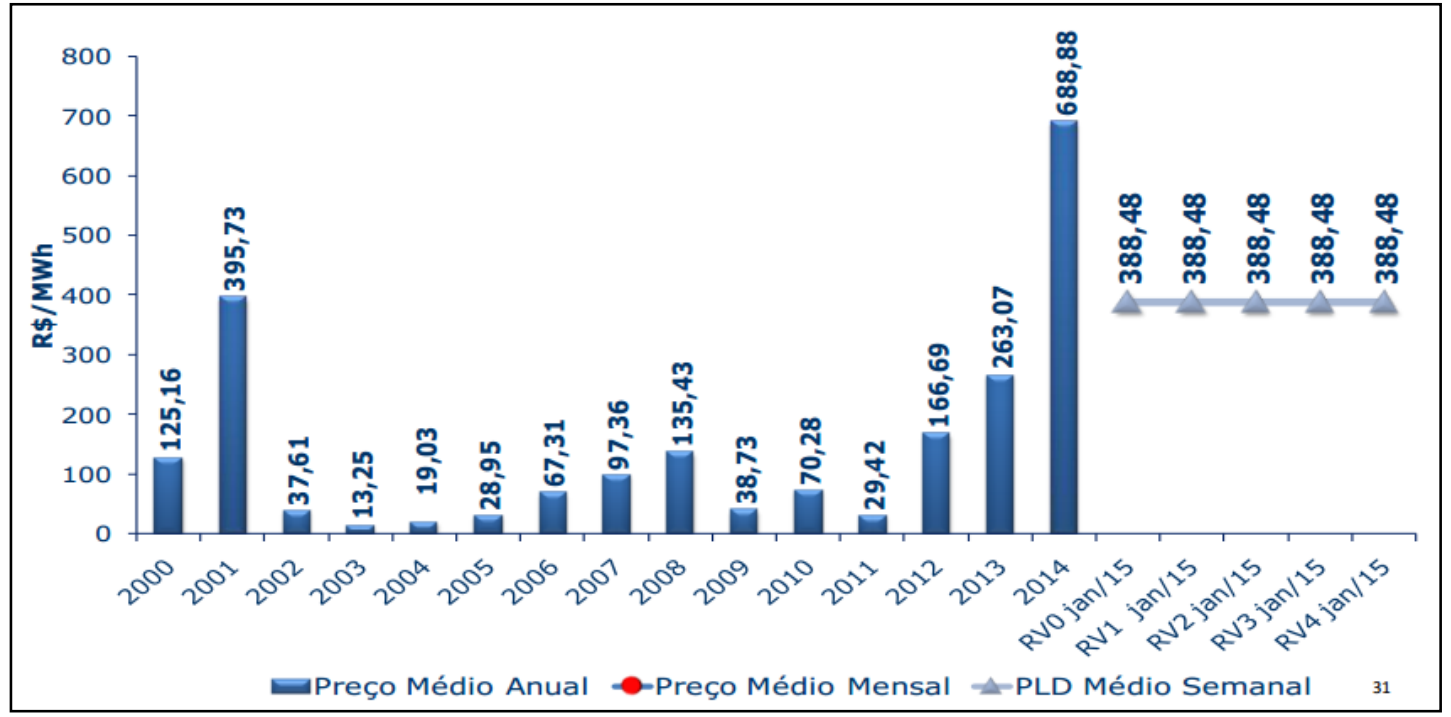

Fonte: CCEE (2015b) 
Pela figura 6, é possível se constatar que 2014 foi o ano com o mais alto PLD apresentado. E cabe ainda ressaltar que o PLD de janeiro de 2015 , R $\$ 388,48$, é o novo máximo definido pela Aneel por meio da Resolução Homologatória $n^{0} 1.832$, de 25 de novembro de 2014.

Mesmo com as estratégias de contratação e geração complementar (citadas anteriormente), os consumidores cooperados podem ficar expostos ao MCP, de forma positiva ou negativa, por algum pico de demanda ou evento inesperado que reduza a produção. Nestas situações, a cooperativa poderá atuar, ainda, como mecanismo de realocação de energia contratual de curto prazo entre seus cooperados.

Isso é possível, pois, conforme citado no capítulo 2, a ANEEL autorizou, a partir de 2014 , a cessão de montantes de energia elétrica e de potência por consumidores livres e especiais. Com isso, passou-se a ser possível que consumidores livres e especiais negociem seus contratos de energia e potência entre si (anteriormente uma atividade não autorizada para os mesmos).

Como a cooperativa já visa ter uma atuação na gestão dos contratos de energia dos seus cooperados, a cooperativa poderia atuar de forma automática e antecipada avaliando as exposições que ocorreriam para o mês, analisando seu custo benefício frente aos preços da energia previstos para o período, e tomando ações de registro de cessão de montantes entre os cooperados para reduzir a exposição a ser paga, gerando compensações internas mais vantajosas para a coletividade.

\section{Complexidade operacional}

Um último foco de atuação da cooperativa, a ser abordado neste trabalho, é como back office operacional centralizado para a operação dos cooperados no mercado livre.

Os processos e regras de atuação no mercado livre ainda são complexos e burocráticos e, de forma similar ao já praticado pelas comercializadoras de energia, a cooperativa realizaria atividades em nome de seus cooperados no registro de contratos, envio e análise das medições, monitoramento de regras e penalidades aplicáveis, recebimento e repasse de notificações da CCEE, representação em assembleias, entre outros processos.

Outra atividade que podem ser concentradas na cooperativa, aliviando as empresas cooperadas de manter pessoal especializado, é a atuação como consultoria técnica e regulatória, apoiando as empresas na adequação ou aplicação da regulação e regras do setor em seus projetos e processos.

Cabe ainda citar que esta forma de atuação foi autorizada, conforme citado no capítulo 2, pela Aneel, em 2013, ao criar a figura do comercializador varejista no mercado livre de Energia Elétrica, que pode realizar a gestão integral da energia e demais responsabilidades de consumidores livres por um agente comercializador integrante da CCEE, classe na qual a cooperativa deverá se registrar na Câmara. 


\section{CONCLUSÃo}

Com base nas informações e na discussão apresentada neste trabalho, é possível se concluir que os problemas que o setor elétrico vem enfrentando, na presente década, irão gerar, ainda, por alguns anos, desafios de atendimento à demanda de energia no Brasil.

As decisões do governo, citadas no trabalho, como a renovação das concessões e o financiamento do déficit das distribuidoras, visam garantir a manutenção do modelo vigente do setor elétrico brasileiro, a viabilidade econômico-financeira das empresas de geração, transmissão e distribuição atuantes no setor, frente às questões que fogem de seu planejamento e, principalmente, a estabilidade de suprimento de energia elétrica para o País. E, por isso, priorizam ações que reduzem os impactos dos problemas para o mercado regulado, que conforme abordado anteriormente, atende as distribuidoras de energia e, por meio das mesmas, a população em geral.

Porém, conforme dados apresentados e analisados na discussão deste trabaIho, isso gera, por sua vez, impactos indiretos para o mercado livre de energia que, em curto e médio prazo, atua como concorrente para a energia elétrica disponível para comercialização no mercado. Dentre os impactos avaliados, os principais são o encarecimento da energia negociada neste mercado, a dificuldade de contratação devido à redução da energia disponível para ser negociada, e, também, o aumento do risco de exposição ao mercado de curto prazo, que atua justamente na liquidação de energia descontratada.

A análise de dados coletados sobre o preço da energia no mercado livre, o seu consumo real e sua estimativa de demanda para os próximos anos e, ainda, o impacto das decisões do governo no montante de energia disponível para negociação, são as bases às discussões do modelo proposto pelo trabalho.

Um importante fator adicional, que trouxe agravamento do cenário acima, é a escassez de chuvas nos últimos anos, da presente década, que traz, também, agravamento ao problema do encarecimento da energia elétrica, por obrigar, nestes momentos, que as gerações mais caras disponíveis sejam utilizadas no País.

Por fim, por meio de uma revisão biográfica do modelo de cooperativa de consumo e de aspectos do setor elétrico brasileiro, foi possível identificar a sua aplicabilidade como modelo de negócio alternativo para reduzir os impactos citados acima na comercialização livre.

Uma cooperativa de consumo de energia elétrica criada para atender pequenos consumidores poderia ser uma opção (real e) viável, do ponto de vista econômico e regulatório, gerando diversos benefícios para os seus cooperados, tais como: a mitigação do risco de exposição a altos preços no mercado livre de energia, garantia de suprimento a preços competitivos, e redução de burocracia a qual os cooperados devem lidar.

Quando, no parágrafo desta conclusão, citou-se que os participantes do mercado livre de energia atuam como concorrentes do mercado regulado na negociação de energia elétrica, no curto e médio prazo, foi porque a viabilização de nova geração 
não se dá em um ciclo curto de tempo. Então, neste cenário de tempo (curto e médio prazo), a energia disponível para ser contratada por ambos os mercados é a mesma.

Porém, esta também é uma atuação viável e de valor agregado para e cooperativa de consumo de energia elétrica, conforme apresentado na discussão do trabaIho, atuando com a força dos cooperados para atrair investimentos e parcerias, e viabilizar novos projetos de geração de energia elétrica que visem atender, exclusivamente, seus cooperados, e em segunda instância, o mercado livre de energia, que ganharia maior liquidez e segurança de suprimento.

\section{REFERÊNCIAS}

ABRACEEL. O papel das comercializadoras. Disponível em: <http://www.abraceel.com.br/zpublisher/secoes/mercado livre.asp?m id=19151>. Acesso em: 20 nov. 2014.

ANEEL. Resolução Normativa $\mathbf{n}^{\circ} \mathbf{5 7 0}$, de 23 de Julho de 2013. Estabelece os requisitos e procedimentos atinentes à comercialização varejista de energia elétrica no Sistema Interligado Nacional - SIN. Diário Oficial da União, Brasília, DF, 01 ago. 2013. p. 65.

Resolução Normativa n 611, de 8 de Abril de 2014a. Estabelece critérios e condições para o registro de contratos de compra e venda de energia elétrica e de cessão de montantes de energia elétrica e de potência, firmados no Ambiente de Contratação Livre - ACL, e dá outras providências. Diário Oficial da União, Brasília, DF, 04 jul. 2014. p.144.

Cadernos Temáticos ANEEL: Micro e mini geração distribuída: sistema de compensação de energia elétrica. Brasília, DF, 2014b.

BRASIL. Constituição (1988). Constituição da República Federativa do Brasil. Brasília, DF, Senado, 1998.

Código Civil. Brasília, DF, Congresso Nacional, 2002.

Lei . $^{\circ}$ 5.764, de 16 de dezembro de 1971. Define a Política Nacional de Cooperativismo, institui o regime jurídico das sociedades cooperativas, e dá outras providências. Diário Oficial da União, Brasília, DF, 16 dez. 1971. p. 10354.

Decreto $n^{\circ} \mathbf{8 . 2 2 1}$, de $1^{\circ}$ de Abril de 2014. Dispõe sobre a criação da Conta no Ambiente de Contratação Regulada e dá outras providências. Diário Oficial da União, Brasília, DF, 02 abr. 2014. p. 1.

Lei $\mathbf{n}^{\circ} \mathbf{1 2 . 7 8 3}$, de 11 de Janeiro de 2013. Dispõe sobre as concessões de geração, transmissão e distribuição de energia elétrica, sobre a redução dos encargos setoriais e sobre a modicidade tarifária; altera as Leis nos 10.438, de 26 de abril de 2002, 12.111, de 9 de dezembro de 2009, 9.648, de 27 de maio de 1998, 9.427, de 26 de dezembro de 1996, e 10.848, de 15 de março de 2004; revoga dispositivo da Lei no 8.631, de 4 de março de 1993; e dá outras providências. Diário Oficial da União, Brasília, DF, 14 jan. 2013. p. 1.

BAUWENS, Thomas. What roles for energy cooperatives in the diffusion of distributed generation technologies? SSRN ELECTRONIC JOURNAL, March, 2014. http://dx.doi.org/10.2139/ssrn.2382596. Disponível em: <https://www.researchgate.net/publication/260421342 What roles for energy cooperatives in the diffusion of distributed generation technologies>. Acesso em: 27 de fevereiro de 2016. 
CAMPOS, Taiane Las Casas. Políticas para stakeholders: um objetivo ou uma estratégia organizacional? Rev. adm. contemp., Curitiba, v. 10, n. 4, Dec.

2006. http://dx.doi.org/10.1590/S1415-65552006000400006.

CARUZZO, Amaury; NOGUEIRA, Luiz Augusto Horta. Avaliação da eficiência energética na iluminação pública: proposta de modelagem considerando a variabilidade climática. Revista Produção Online, Florianópolis, SC, v.15, n. 4, p. 1399-1425, out./dez.

2015. http://dx.doi.org/10.14488/1676-1901.v15i4.1974

CCEE. Procedimentos de comercialização - Módulo 3 - Contratação de energia e potência - Submódulo 3.1 - Contratos do ambiente livre. São Paulo, SP, nov. 2013a. Disponível em: <http://www.ccee.org.br/portal/faces/pages publico/o-que-fazemos? adf.ctrlstate $=8903$ txzv3 45\& afrLoop=970872239345932 $>$. Acesso em: 20 de novembro, 2014.

. Apresentação do curso visão geral das operações na CCEE. Disponível em: $<$ http://www.ccee.org.br/search/query/redirect.jsp?qid $=47818 \&$ did=131179\&pos=1\&idx=1\&fid=\&pdfq=\%22vis\%C3\%A3o\%20geral\%22>. Acesso em: 20 de novembro de 2014b.

Procedimentos de comercialização - Módulo 5 - Mercado de curto prazo Submódulo 5.1 - Contabilização e recontabilização. São Paulo, SP, fev. 2013b. Disponível em: <http://www.ccee.org.br/portal/faces/pages publico/o-que-fazemos? adf.ctrlstate=11xjhgqf0o $4 \&$ afrLoop=1121995341112112 . . Acesso em: 22 de novembro de 2014.

Entenda o setor elétrico. Disponível em: <http://www.ccee.org.br/portal/faces/pages publico/onde-atuamos/setor eletrico>. Acesso em: 20 de novembro de 2014a.

O que fazemos - Preços. Disponível em: $\leq$ http://www.ccee.org.br/portal/faces/pages publico/o-que-fazemos? adf.ctrl-state=11xjhggf0o 4\& afrLoop=1124940207866263 $>$. Acesso em: 22 nov. 2014c.

. Relatório InfoMercado - Jan./2013. São Paulo, SP, Janeiro. 2013c. Disponível em: $\leq$ http://www.ccee.org.br/portal/faces/pages publico/quem-somos/informacoesmercado/info mercado>. Acesso em: 10 jan. 2015.

Relatório InfoMercado - Jan./2014. São Paulo, SP, Janeiro. 2014d. Disponível em: <http://www.ccee.org.br/portal/faces/pages publico/quem-somos/informacoesmercado/info mercado>. Acesso em: 10 jan. 2015.

Relatório InfoMercado - Jan./2015. São Paulo, SP, Janeiro. 2015a. Disponível em: <http://www.ccee.org.br/portal/faces/pages publico/quem-somos/informacoesmercado/info mercado>. Acesso em: 10 jan. 2015.

. Relatório InfoPLD - Fev./2015. São Paulo, SP, Janeiro. 2015b. Disponível em: <http://www.ccee.org. $\mathrm{br} /$ portal/faces/pages publico/o-que-fazemos/como ccee atua/precos/info pld? >. Acesso em: 10 fev. 2015.

CRISTALDO, Márcia Ferreira; ORTEGA, Jeferson Meneguim. Análise econômico-financeira da utilização do gn em sistemas de cogeração aplicados a instalações prediais. Revista Produção Online, v.9, n.2, p.230-242, jun. de 2009. http://dx.doi.org/10.14488/16761901.v9i2.268. 
COMERC. Panorama semanal - 05/08/2013. São Paulo, SP, ago. 2013. Disponível em: <http://www.comerc.com.br/conteudo/panoramas/Panorama semanal $0508 \quad 13$ 1.pdf>. Acesso em: 22 nov. 2014.

EPE. Projeção da demanda de energia elétrica para os próximos 10 anos (2014-2023). Rio de Janeiro, 2013. Nota técnica.

KAUARK, Fabiana. Metodologia da pesquisa: guia prático. Itabuna: Via Litterarum, 2010.

MEDEIROS, Carolina. MP 579 impõe reestruturação do setor. Canal Energia, São Paulo, SP, dez. 2012. Disponível em: http://www.canalenergia.com.br/zpublisher/materias/Retrospectiva.asp?id=92996\&a=2012. Acesso em: 25 jan. 2015.

MME/EPE. Plano decenal de expansão de energia 2023. Brasília, 2014

RECEITA FEDERAL. Página de dúvidas sobre declaração. Disponível em: <http://www.receita.fazenda.gov.br/publico/perguntao/dipj2013/Capitulo XVII SociedadesCooperativas 2013.pdf>. Acesso em: 18 out. 2014.

SEBRAE, Cooperativas: série empreendimentos coletivos. Brasília, DF, Sebrae, 2009, 48 p.

SAGEBIEL, Julian; MÜLLER, Jakob R.; ROMMEL, Jens. Are consumers willing to pay more for electricity from cooperatives? Results from an online Choice Experiment in Germany. Energy Research \& Social Science, v. 2, p. 90-101, 2014. Disponível em:

$<$ https://mpra.ub.uni-muenchen.de/52385/1/MPRA paper 52385.pdf>. Acesso em: 8 de março de 2016.

TRADE ENERGY. Mercado em foco - Ed. 16. São Paulo, SP, out. 2012. Disponível em: <http://www.tradeenergy.com.br/comunicacao-informativos.php >. Acesso em: 25 jan. 2015.

Mercado em foco - Ed. 40. São Paulo, SP, out. 2014a. Disponível em: <http://www.tradeenergy.com.br/comunicacao-informativos.php>. Acesso em: 25 jan. 2015.

Mercado em foco - Ed. 38. São Paulo, SP, ago. 2014b. Disponível em: <http://www.tradeenergy.com.br/comunicacao-informativos.php $>$. Acesso em: 25 jan. 2015.

VARIAN H. R. Microeconomia. Rio de Janeiro: Campus, 8. ed. edição, 2012.

YILDIZ, Özgür et al. Renewable energy cooperatives as gatekeepers or facilitators? Recent developments in Germany and a multidisciplinary research agenda. Energy Research \& Social Science, v. 6, p. 59-73, 2015.

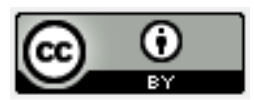

Artigo recebido em 28/12/2015 e aceito para publicação em 06/04/2016 DOI: http://dx.doi.org/ 10.14488/1676-1901.v16i3.2305 